\title{
Records of ancient cosmic radiation in extraterrestrial rocks*
}

\author{
NARENDRA BHANDARI \\ Physical Research Laboratory, Ahmedabad 380 009, India
}

\begin{abstract}
Recent results on cosmic ray interactions in lunar samples and meteorites resulting in production of stable and radionuclides, particle tracks and thermoluminescence are reviewed. A critical examination of ${ }^{26} \mathrm{Al}$ depth profiles in lunar rocks and soil cores, together with particle track data, enables us to determine the long term average fluxes of energetic solar protons $(>10 \mathrm{MeV})$ which can be represented by $\left(J_{s}, R_{0}\right)=(125,125)$. The lunar rock data indicate that this flux has remained constant for $5 \times 10^{5}$ to $2 \times 10^{8}$ years.

Production rates of stable and radionuclides produced by galactic cosmic rays is given as a function of size and depth of the meteoroid. Radionuclide $\left({ }^{53} \mathrm{Mn},{ }^{26} \mathrm{Al}\right)$ depth profiles in meteorite cores, whose preatmospheric depths are deduced from track density profiles are used to develop a general procedure for calculating isotope production rates as a function of meteoroid size. Based on the track density and ${ }^{22} \mathrm{Ne} /{ }^{21} \mathrm{Ne}$ production rates, a criterion is developed to identify meteorites with multiple exposure history. ${ }^{22} \mathrm{Ne} /{ }^{21} \mathrm{Ne}$ ratio $<1.06$ is usually indicative of deep shielded exposure. An examination of the available data suggests that the frequency of meteorites with multiple exposure history is high, at least $15 \%$ for $L L, 27 \%$ for $L$ and $31 \%$ for $\mathrm{H}$ chondrites. The epi-thermal and the thermal neutron density profiles in different meteorites are deduced from ${ }^{60} \mathrm{Co}$ and track density data in Dhajala, Kirin and Allende chondrites. The data show that the production profile depends sensitively on the size and the chemical composition of the meteoroid.

Cosmic ray-induced thermoluminescence in meteorites of known preatmospheric sizes has been measured which indicates that its production profile is nearly flat and insensitive to the size of the meteoroid.

Some new possibilities in studying cosmic ray implanted radionuclides in meteorites and lunar samples using resonance ionisation spectroscopy are discussed.
\end{abstract}

Keywords. Solar cosmic rays; meteorites; particle tracks; thermoluminescence; lunar samples; radioactivity; resonance ionisation spectroscopy.

\section{Introduction}

The chemical and mineral constituents of rocks, exposed to cosmic radiation undergo atomic and nuclear transformations, which are now well established. The cosmic ray interactions thus result in the following effects:

(i) Nuclear species, both stable and radioactive, produced in nuclear reactions, mainly by cosmic ray primary and secondary protons, alpha particles and neutrons with target elements present in the rock material.

(ii) Particle tracks produced in crystalline material due to intense ionisation produced by heavy nuclei $(Z>20)$.

(iii) Thermoluminescence produced by charged particles, mainly low energy protons, in crystalline material.

In addition, a heavy dose of charged particles, due to exposure to solar wind and solar flares, produces radiation damage which can be easily identified in the surface regions of mineral grains.

*Paper presented at the second national seminar-cum-workshop on the use and application of solid state nuclear track detectors held at Physical Research Laboratory, Ahmedabad, India, during 24-26 February 1981. 
Characteristics of cosmic rays in the remote past have been deduced from a study of such records in meteorite, lunar and terrestrial samples. In this way, the energy spectra, composition and their spatial and temporal variation in the interplanetary space have been deduced. Several exhaustive reviews of the work done in this field exist (Lal 1972, 1977; Reedy et al 1981; Walker 1975; Bhandari and Rao 1980) and therefore we confine our discussion to a critical assessment of some new results obtained in the last few years. The subject of cosmic ray production of tracks in lunar and meteorite minerals and their implications to the exposure history of meteorites has been covered in another paper appearing in this issue (Goswami 1981).

As all these samples are subjected to a number of natural processes, occurring simultaneously while the cosmic ray effects are accumulating, the resultant records are complex composites of several components which depend upon the exposure history and exposure geometry of individual samples. Here we describe some of the basic features of these records in meteorites and lunar samples and their limitations in deducing the characteristics of ancient cosmic rays.

\section{Solar cosmic rays}

Rocks and soil exposed on the lunar surface serve as excellent detectors for some components of solar and galactic cosmic rays. However, a large number of processes occur in the lunar regolith such as erosion by micrometeorites and solar wind, fragmentation of rocks, repeated burial and excavation, shock heating and collisional melting, which modify these records to an extent that it is difficult to use them directly to deduce cosmic ray fluxes. After examining a large number of the most favourable cases, it has now been realised that there are no lunar rocks which have had a simple one-stage exposure on the moon. Thus the geometry in which the rocks are found on the moon represents only the terminal phase of their exposure. Since almost all the rocks have either been fragmented, multiply exposed at various times in different geometries at different depths or have been shocked, it is difficult to use them as cosmic ray detectors until their exposure history is fully understood. This complex exposure is the main cause for the fact that exposure ages of rocks obtained by different methods i.e. tracks, radioisotopes, raregases, microcraters, neutron effects etc. are not concordant (Lal 1977). A rock with a simple one-stage exposure will be characterised by concordant exposure ages by all these methods but no such case has been found so far. Also rocks lying on the lunar surface undergo change in geometry, typically on time scales of a million years so that the earlier solar cosmic ray (SCR) records are usually disturbed in the lunar rocks and cannot be easily understood.

In order to deduce solar flare fluxes using lunar rocks it is therefore not adequate to measure any of the cosmic ray produced effects mentioned above; rather several types of studies have to be conducted simultaneously on carefully selected samples. In our laboratory we have adopted a procedure for understanding the exposure history of a sample, determination of erosion effects and surface exposure ages (Bhandari et al 1975; Bhattacharya and Bhandari 1975). This approach seems to be quite satisfactory for selecting a proper sample for cosmic ray studies and is described below.

The surface orientation of a large number of lunar rocks on the moon's surface is well documented from lunar surface photography of these samples. Of these, low 
exposure age rocks ( 5 m.y. or less), as determined by rare gas data, were selected. Track density profiles in several sections of surface chips were measured. The track density at various depths $(X)$ within a lunar rock $\rho(X)$ divided by the track production rate $\dot{\rho}(X)$ gives a curve such as shown in figure 1 . The steeply rising part of this curve at shallow depths $(<1 \mathrm{~mm})$ allows us to estimate the erosion rate of the rock on the moon and the flatter part at depths $>1 \mathrm{~mm}$ reflects the exposure history which, in some favourable cases of a single-stage exposure on the lunar surface, develops into a plateau and enables us to estimate the surface exposure age of the rock to galactic cosmic rays (GCR) (Bhattacharya and Bhandari 1975). In the case of rocks which show a well-defined plateau, the solar flare exposure age equals the galactic cosmic ray exposure age. The error in the estimate of such an exposure age is mainly due to the uncertainty in the average track production rates in the past. Various estimates of the production rates (Yuhas and Walker 1973; Bhandari et al 1971; see also Goswami 1981) agree within about $20 \%$ at the depths of interest. Only rocks where tracks and rare gas exposure ages are (nearly) concordant were then considered suitable for further analysis of radioisotopes.

In this way, we were able to select five lunar rocks $61016,64435,66095,75035$ and 79215 with known solar flare exposure history and orientation on the lunar surface. These are listed in table 1. Also included are rocks 12002, 14310, 14321 and 68815, studied by other groups (Wahlen et al 1972; Kohl et al 1978) for solar flare records. Of these the rock 61016 is the most suitable because it has the closest concordance of $\mathrm{He}, \mathrm{Ne}$, and track ages. Others like 75035, 12002, 14321 have discordant exposure ages as determined by various methods.

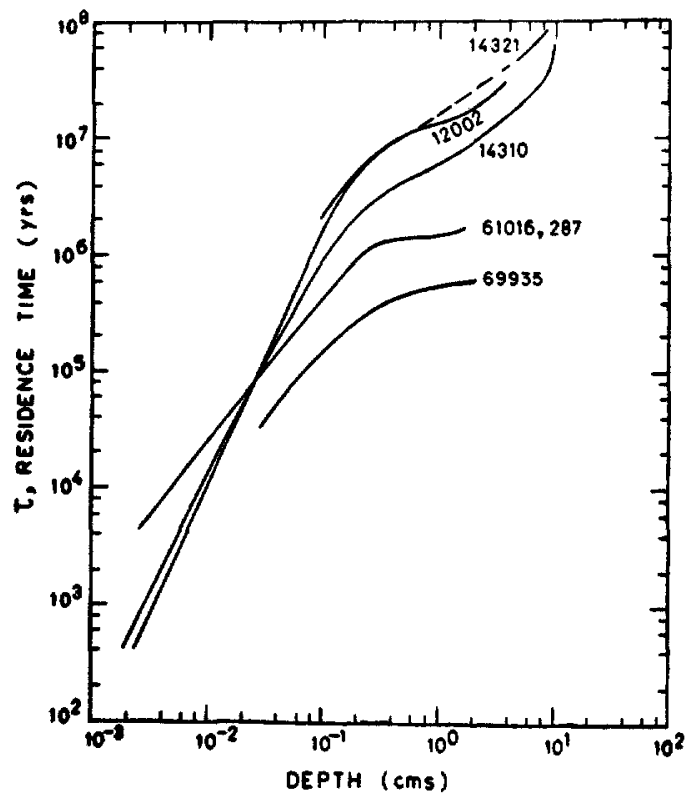

Figure 1. The exposure age plateau curve. The apparent residence time for various rocks is plotted as a function of depth. 61016 shows a good plateau in $0.2-2 \mathrm{~cm}$ range showing a simple exposure history with surface exposure age of $1.5 \mathrm{~m}$.y. Other rocks 12002,14310 and 14321 do not show any plateau indicative of complex exposure history with short surface residence time. (After Bhandari et al 1975) 


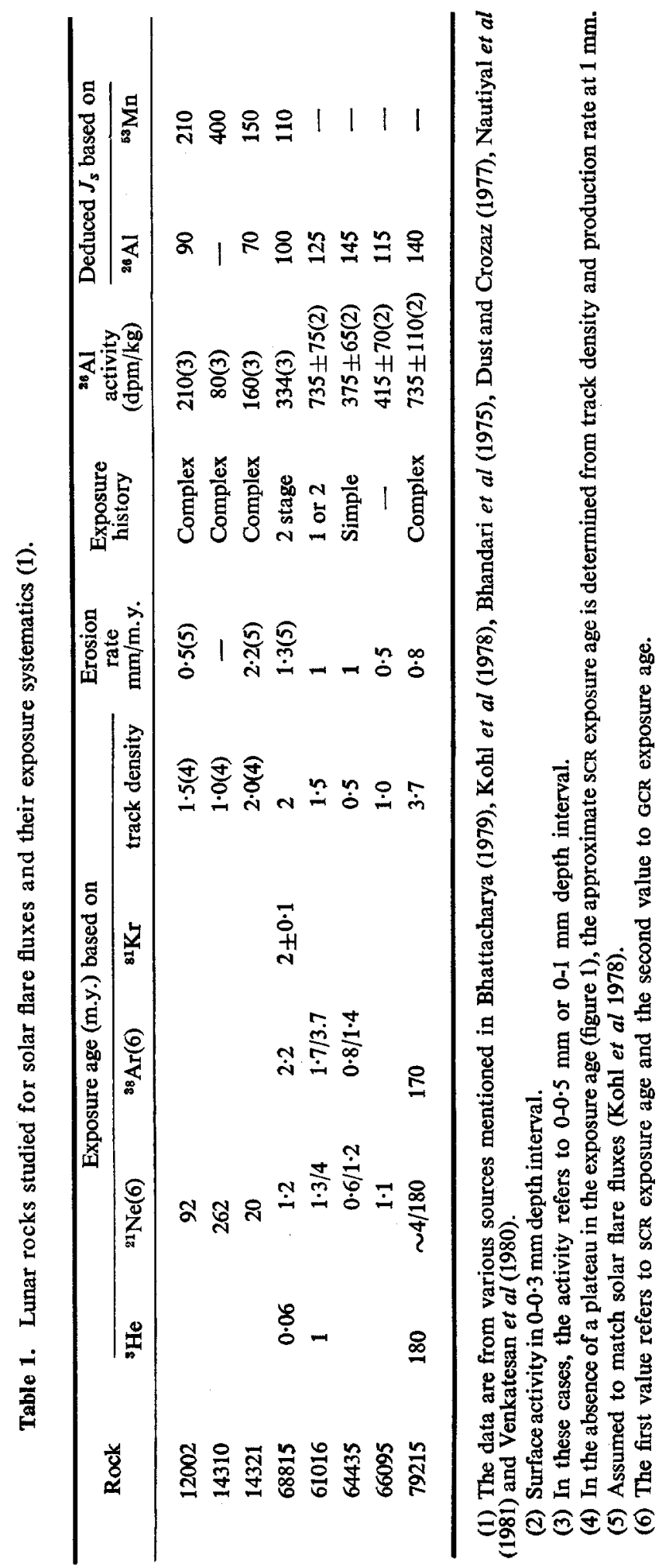


The slope $(\beta)$ of the curve shown in figure 1 gives the erosion rate (Bhattacharya and Bhandari 1975). This has been calculated for each rock studied by our group and the values are given in table 1. For others the assumed erosion rates are given. The plateau region is nearly flat in some of these rocks as shown by the typical case of 61016. In other cases e.g. 12002, 14310 and 14321 there is no plateau indicative of a complex exposure history and short ( $\leqslant 1 \mathrm{~m} . \mathrm{y}$.) exposure age on the lunar surface.

The surface chips of these rocks were microscopically examined for microcraters and it was found that only a part of the surface had remained well preserved and some areas had apparently suffered attrition. The well-preserved areas can also be easily distinguished by surface albedo, particularly in the case of anorthositic rocks. The well preserved area were selected for ${ }^{26} \mathrm{Al}$ measurements as described below (Bhandari et al 1975).

The ${ }^{26} \mathrm{Al}$ activity produced in the top layer (mean thickness $90 \mathrm{mg} / \mathrm{cm}^{2}$ ) of rocks $61016,64435,66095,75035$ and 79215 were measured by the non-destructive $\beta-\gamma$ coincidence technique (Bhandari 1977). This technique not only offers a very high depth resolution, determined by the half thickness of ${ }^{26} \mathrm{Al}$ decay positrons, but also allows selection of the surface area to be counted. The surface activity of ${ }^{26} \mathrm{Al}$ determined by this method is given in table 1 .

Two of the rocks 61016 and 66935 were chosen for a more detailed depth profile using radiochemical separation techniques for ${ }^{26} \mathrm{Al}$. The observed depth profile in rock 61016 is shown in figure 2. This has been determined nondestructively by $\beta-\gamma$ counting as well as after radiochemical separation of ${ }^{26} \mathrm{Al}$ (Potdar 1981; Bhandari et al 1981b). These data can be used to determine the solar flare proton energy spectrum, which is responsible for ${ }^{26} \mathrm{Al}$ production, after taking into account the target element abundance, erosion rate and the lunar orientation of the sample. The solar flare flux $J(>10 \mathrm{MeV})$ as a function of rigidity $R$ of the particles is usually represented in the form

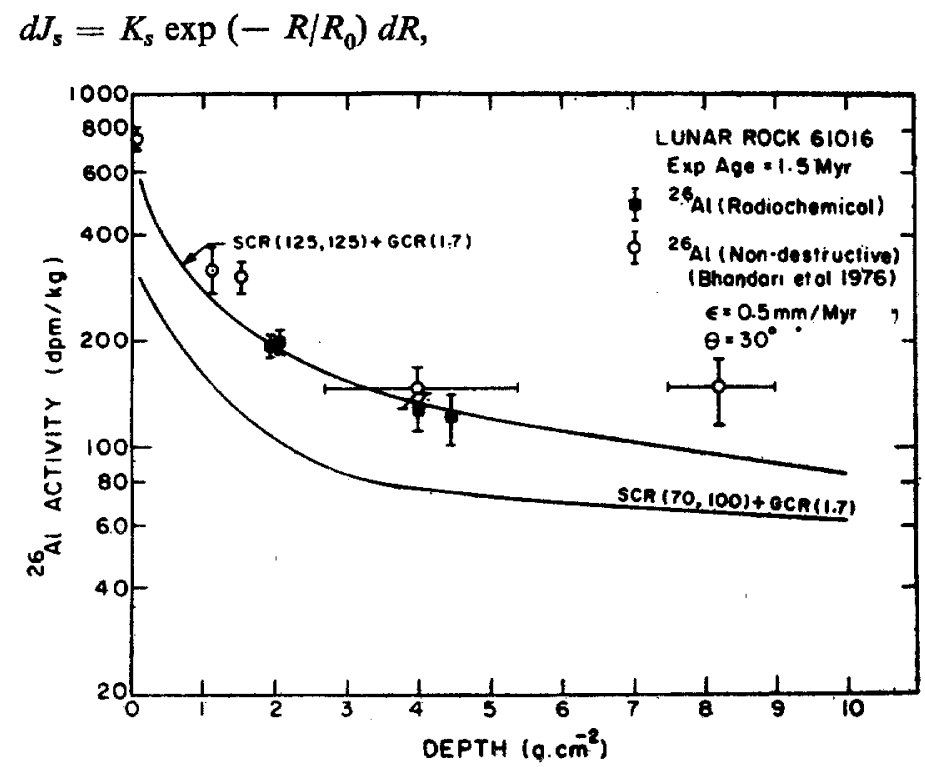

Figure 2. The measured ${ }^{2 B} \mathrm{Al}$ activity in rock 61016 is plotted as a function of depth. The thick curves are production profiles expected for SCR and GCR parameters as indicated (Bhandari, Potdar and Shukla, in preparation). $c$ is the erosion rate and $\eta$ is the zenith angle of the rock chip on the moon. 
where $R_{0}$ is the characteristic rigidity. We have calculated production rates with various sets of $J_{s}$ and $R_{0}$ to find the best match with the observed values. The results as shown in figure 2 indicate that $\left(J_{s}, R_{0}\right)=(125,125)$ best reproduce the observed profiles. It should be noted, as pointed out by Wahlen et al (1972), that the estimation of $J_{s}$ or $R_{0}$ individually is not unique but other combinations with higher $J_{s}$ and lower $R_{0}$ or vice versa would reproduce the observations equally well.

Some other groups (Boeck1 1972; Begemann et al 1972; Kohl et al 1978 and others) have also made attempts to determine the solar flare fluxes in the past based on radionuclides ${ }^{26} \mathrm{Al},{ }^{53} \mathrm{Mn},{ }^{14} \mathrm{C}$ and rare gas isotopes e.g. ${ }^{3} \mathrm{He}$ (Venkatesan et al 1980), and deduced flux parameters which ranged between $\left(J_{s}, R_{0}\right)=(70-200,80-150)$. Whether such a large range of parameters represents actual time variations in solar flare fluxes or due to inherent uncertainties in the technique applied or due to improper sample studied as discussed above, has been a matter of intense debate. Time variations in solar flare and radiation fluxes have important implications to the stellar structure and affects the planetary climates and interplanetary medium (Eddy 1976). We should, however, exclude other possible causes for this wide range of parameters before they are attributed to solar variations. As pointed out earlier, there are several problems in deducing the correct flux from lunar rock data. These include corrections for exposure geometry, exposure history and erosion rate applicable to each rock which have to be independently inferred. In the radioisotopic work the most serious error arises from the assumption usually made that the rocks are saturated i.e. exposed for a time long enough to bring the radioisotope production in secular equilibrium with its decay. Though this assumption is usually valid for short-lived nuclides like ${ }^{14} \mathrm{C}$, it is clear from the vast amount of work on microcraters, tracks and rare gases that no rocks are exposed for so long ( $>10^{7}$ years) on the lunar surface as to let ${ }^{53} \mathrm{Mn}$ to be saturated. The assumption is also not valid for ${ }^{26} \mathrm{Al}$ except in some rare cases where the surface exposure age of the rock is $z 5 \times 10^{6}$ years. Most of these estimates therefore tend to give lower fluxes which should be corrected for undersaturation. The rocks 12002, 14310, 14321, etc. (Wahlen et al 1972; Kohl et al 1978) have had a short surface exposure as determined by track density profiles. The flux of $(70,100)$ deduced from the ${ }^{26} \mathrm{Al}$ and ${ }^{53} \mathrm{Mn}$ profile in these rocks, which has not been corrected for exposure age, is therefore in error. In the case of rare gas isotopes the diffusion losses during micrometeorite impacts and shock melting are serious as pointed out by Yaniv (1981). Furthermore the rare gases produced in pre-surface expsoure, which are sometimes partially retained by the rock may lead to serious uncertainties in estimating correct depth profile due exclusively to solar flare production.

Unfortunately there is no independent method, which gives an accurate estimate of the exposure ages, other than the track density profiles. The track method also works only in some favourable cases of simple exposure as discussed earlier. The rock 68815 , whose exposure age is determined by ${ }^{81} \mathrm{Kr}-{ }^{83} \mathrm{Kr}$ method to be 2 m.y. (Behrmann et al 1973) has been studied in detail for ${ }^{26} \mathrm{Al}$ and ${ }^{53} \mathrm{Mn}$ (Kohl et al 1978). The ${ }^{81} \mathrm{Kr}-{ }^{-83} \mathrm{Kr}$ age refers to the GCR age and not to the surface exposure or the suntan age. The track density profiles measured by Behrmann et al (1973) and Dust and Crozaz (1977) indicate that small-scale chipping of the rock cannot be ruled out. The plateau method indicates two-stage irradiation, probably due to a minor fragmentation event during the past 2 m.y. It is difficult to estimate the sun-tan age of this rock but this should be smaller than 2 m.y. 
Lunar soil cores offer another set of samples for the estimation of solar flare fluxes. Except for the top few millimetres where the stratigraphy is disturbed by micrometeorite gardening, the soil column is generally static on a million year time scale and the uncertainty of short exposure age, as in the case of rocks, can be eliminated. The ${ }^{26} \mathrm{Al}$ data in Apollo 15 drive core tube (Fruchter et al 1976) are shown in figure 3. Similar measurements have been made in other drive tubes and Fruchter et al (1981) found that the observed integral flux is $60 \%$ more than the value calculated from SCR flux $\left(J_{s}, R_{0}\right)=(70,100)$ and the GCR flux of $1.7 \mathrm{p} /\left(\mathrm{cm}^{2} \sec 4 \pi\right)$. The radioactivity integrated over the length of the core must match the production rate, irrespective of gardening, unless the top soil is physically transported to or away from the sampling site by some mechanism. The flux of $(70,100)$ is therefore clearly inadequate to explain the observed activity. If we ignore the top few millimetres which may have been accumulated from deep cratering event recently or disturbed by gardening, it is clear from figure 3 that a good match between the observed and calculated fluxes is obtained if $\left(J_{s}, R_{0}\right)$ is taken to be $(125,125)$. We thus find the core tube data support the flux estimates of $(125,125)$ deduced from rock 61016 . This flux would also explain the activity level observed in rock 14310 which has a sun-tan age of $1 \mathrm{~m} . \mathrm{y}$. (Kohl et al 1978).

The short-lived isotopes ${ }^{14} \mathrm{C}$ (meanlife $8200 \mathrm{yr}$ ) and ${ }^{81} \mathrm{Kr}$ (meanlife $3 \times 10^{5} \mathrm{yr}$ ) yield fluxes of $\left(J_{s}, R_{0}\right)=(200,100)$ (Begemann et al 1972; Regnier et al 1979; Reedy $1980)$. Assuming $(70,100)$ to be flux values over $10^{6}-10^{7}$ yr., Reedy $(1980)$ and Zook (1980) have argued that the ${ }^{14} \mathrm{C},{ }^{81} \mathrm{Kr}$ and TL data support time variation of the average solar flare fluxes and indicate that the flux over the past $10^{3}-10^{5}$ years has been higher than during $10^{6}-10^{7}$ yrs. Although from the arguments presented above, it appears that all the nuclides are consistent with $\left(J_{s}, R_{0}\right)=(125,125)$ or probably, with somewhat higher fluxes. Therefore the proposed variations need to be confirmed by better cross-section and activity measurements.

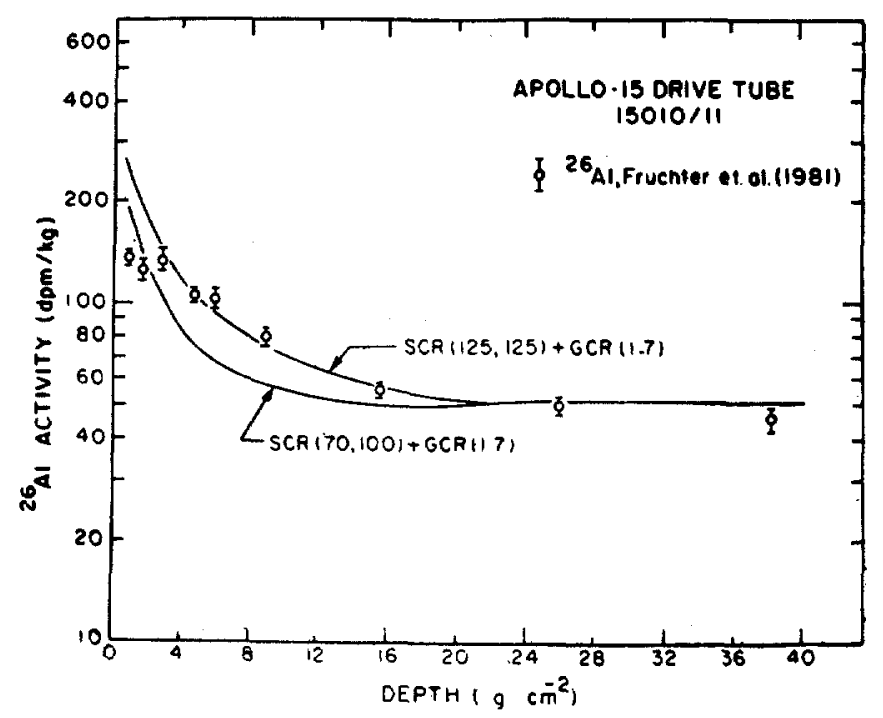

Figure 3. The measured ${ }^{20} \mathrm{Al}$ activity in Apollo 15 drive core tube 15010/11. The solid curves indicate the expected profiles for the SCR and GCR parameters as indicated (Bhandari, Potdar and Shukla, in preparation). 


\section{Constancy of solar flare particle fluxes}

Variations in the frequency and intensity of solar flares with the sun spot cycle are well established. The average solar flare fluxes over the solar cycle 19 was $(378,100-$ $130)$, this being the most active sun spot cycle recorded in the last two centuries with sun spot number $R_{\max }=210$. Compared to this, solar cycle $20 \mathrm{had}, R_{\max }=110$ and average $\left(J_{s}, R_{0}\right)=(90,85)$ (Reedy 1977; Goswami et al 1981; Potdar 1981). This has led to speculations about long term variations in the solar activity. Because of the immense influence the sun has on the terrestrial climate, there has recently been a renewed interest to examine the relationship of major climatic changes on the earth in the past and the variations in the energy out-flux from the sun. Experimentally, it is an extremely difficult problem. At least for the past few decades where reliable data are available, the solar radiation output has been found to be remarkably constant, within about $1 \%$ (Kondrateyev and Nikolsky 1970) even as the particle flux from the sun has changed significantly as mentioned above (Reedy 1980; Potdar 1981). Statistically, the solar constant seems to be related to the sunspot number (Kondrateyev and Nikolsky 1970). If the radiation and corpuscular flux are related, it appears from these data that the variations in the radiation flux from the sun are magnified by several orders of magnitude in the corpuscular flux. Solar corpuscular flux, particularly of the high energy components, is easy to estimate from its nuclear effects in rocks. Lunar rocks thus provided an opportunity to determine variation in the time averaged $\left(5 \times 10^{5}-2 \times 10^{6} \mathrm{yr}\right)$ energetic proton flux in the past (Bhandari et al 1976).

The rocks, listed in table 1, were exposed for different periods of time on the lunar surface. The activity of ${ }^{26} \mathrm{Al}$ was measured in the top layer of the rock, selectively in a thin layer (mean thickness $300 \mu$ ) defined by the range of aluminium-26 decay positrons as discussed earlier. The results are shown in figure 4 . The activity in all rocks cluster around the expected level defined by $\left(J_{s}=125, R_{0}=125\right)$, thus showing

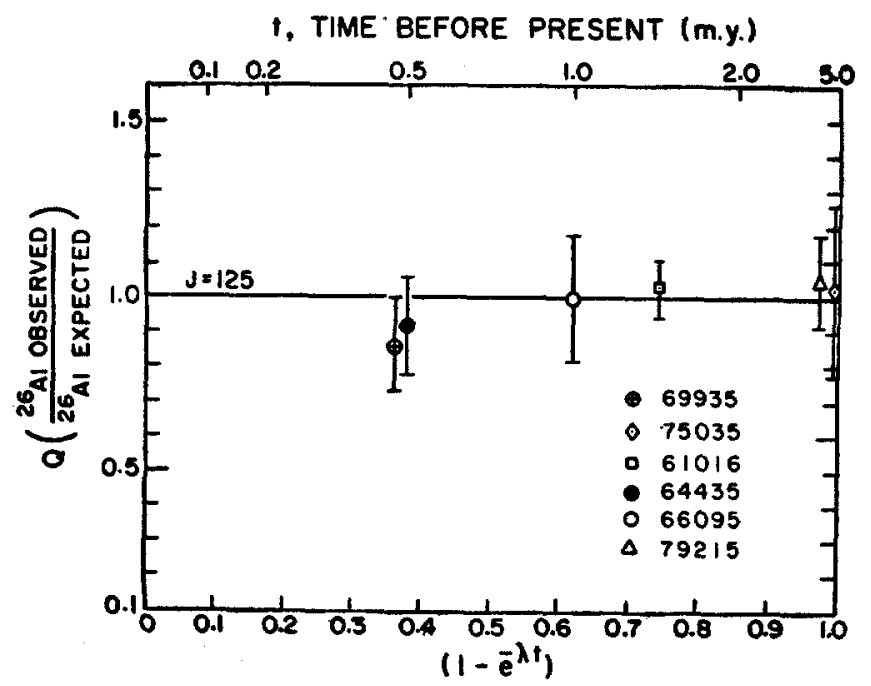

Figure 4. Ratio of the observed to expected ${ }^{26} \mathrm{Al}$ activity (based on $J_{s}=125, R_{0}=125$ ) $Q(t)$, as a function of time, measured in Apollo rocks (After Bhandari et al 1975). The deviation of $Q$ from unity is small which rules out major changes in solar flare activity in the past. 
that the average solar proton fluxes ( $>10 \mathrm{MeV}$ ) integrated over the exposure age of the rocks have not varied beyond a level which is well within the errors of measurement.

\section{Cosmic ray effects in meteorites}

\subsection{Production of spallation products}

Meteorites are excellent monitors of cosmic ray intensity in the remote past since they are exposed to the cosmic rays in the inner solar system for time periods usually ranging from $10^{6}$ to $10^{9}$ years. The main difficulty arises from the fact that (i) their shape is significantly modified due to ablation during their atmospheric transit so that their geometry of exposure in space is not known and (ii) the dependence of production rates $P\left(X, R_{E}\right)$ as a function of depth $(X)$ and size $\left(R_{E}\right)$ on the primary cosmic ray spectrum is not known accurately.

The production $P_{i}$ of a nuclide, from target nuclei $j$ at a depth $X$ in a spherical body of radius $R_{E}$ depends on the target element abundance, $N_{j}$, excitation function $\sigma_{i j}$ and flux of energetic nucleons $\phi\left(E, X, R_{E}\right)$ above the threshold energy $E_{T}$ and is given by

$$
P_{i}\left(X, R_{E}\right)=\sum_{j} \int_{E_{T}}^{\infty} N_{j} \cdot \sigma_{i j}(E) \cdot \phi\left(E, X, R_{E}\right) d E
$$

The excitation function $\sigma_{i j}$ is known for several reactions (Tobailem 1977; Reedy and Arnold 1972) but still not available for many important reactions of interest, particularly for those induced by neutrons. $\phi\left(E, X, R_{E}\right)$ is also not known accurately although several attempts have been made to calculate the energy spectrum by Lavrukhina and Ustinova (1972), Kohman and Bender (1967) and Reedy and Arnold (1972). The accuracy of these calculations for production rates of various nuclides has however not yet been established although the measured concentrations of spallation products in most meteorites lie in the predicted range. Only in the case of Marjalhati pallasite, Bhattacharya et al (1980a) found that the measured profile of ${ }^{53} \mathrm{Mn}$ agrees with the calculated profile given by Kohman and Bender (1967). Recently Bhattacharya et al (1980b) and Bhandari and Potdar (1981) applied the Reedy-Arnold approach, as first used for calculating isotope production in the moon, to the case of meteorites and calculated the production rates of several stable and radionuclides. In the Reedy-Arnold formulation, the energy spectrum (primary + secondary) within the meteorite of radius $R_{E}$ at any depth $X$ is assumed to have the form

$$
\phi\left(E, X, R_{E}\right)=k\left(X, R_{E}\right)\left\{a\left(X, R_{E}\right)+E\right\}^{-2.5},
$$

where $a$ is the spectral hardness parameter and $k$ is the normalizing constant given by

$$
k\left(X, R_{E}\right)=\frac{{ }^{3 J_{G}}\left(>1000 \mathrm{MeV}, X, R_{E}\right)}{2}\left\{a\left(X, R_{E}\right)+1000\right\}^{1.5},
$$


where $J_{G}$ is the integral flux (above $1000 \mathrm{MeV}$ ) calculated from the attenuation of nucleons and fragmentation of alpha particles (and heavier nuclei) based on the primary flux

$$
F_{0}=J_{G}\left(X=0, R_{E}=0\right)=1.7 \mathrm{p} / \mathrm{cm}^{2} . \sec 4 \pi s r
$$

At any depth $X$,

$$
\begin{aligned}
J_{G}\left(X, R_{E}\right) & =\int_{0}^{2 \pi} d \phi \int_{0}^{\pi}\left[F_{0} \exp \left(-r / \lambda_{P}\right)+a F_{0} \exp \left(-r / \lambda_{a}\right)\right. \\
+ & \left.\frac{a b F o}{d}\left\{\exp \left(-r / \lambda_{P}\right)-\exp \left(-r / \lambda_{a}\right)\right\} /\left(\frac{1}{\lambda_{a}}-\frac{1}{\lambda_{P}}\right)\right] \sin \theta d \theta
\end{aligned}
$$

where $\theta$ and $\phi$ are the zenith and azimuth angles and $r=r\left(X, R_{E}, \theta\right)$, distance of any point $P$ from the surface along $\theta$ (Bhattacharya et al 1973a).

$$
r=-\left(R_{E}-X\right) \cos \theta+\left\{R_{E}^{2} \cos ^{2} \theta+2 R_{E} X \sin ^{2} \theta-X^{2} \sin ^{2} \theta\right\}^{1 / 2}
$$

where $a=$ fraction giving the flux of alpha particles relative to protons, $b=$ coefficient expressing the contribution to the flux from fragmentation of the alpha particles, $d=$ interaction mean free path of alpha particles and

$$
\frac{1}{\lambda_{P}}=\frac{1}{A}+\frac{1}{B}, \quad \text { and } \quad \frac{1}{\lambda_{\alpha}}=\frac{1}{C}+\frac{1}{D}
$$

where $A$ and $C$ are attenuation mean free paths and $B$ and $D$ ionisation mean free paths of protons and alpha particles respectively (Reedy and Arnold 1972).

We have experimentally determined the depth profiles of ${ }^{53} \mathrm{Mn}$ in meteorites whose preatmospheric sizes were determined by studying heavy ion tracks (Bhattacharya et al 1980b; Bhattacharya 1979). Assuming that these meteorites have been exposed to "normal" flux of galactic cosmic rays $\left(1.7 \mathrm{p} / \mathrm{cm}^{2} . \mathrm{sec} 4 \pi s r\right)$ and the energy spectrum of primary and secondary nucleons in the meteoroid is determined by the spectral shape parameter $a\left(X, R_{E}\right)$ as in the Reedy-Arnold formulation, the values of a were calculated from equations 1,2 and 3. The values of $\alpha$ (figure 5 ) and $\sigma(E)$ can then be used to deduce the production rates of other isotopes of interest such as ${ }^{26} \mathrm{Al},{ }^{21} \mathrm{Ne}$, ${ }^{22} \mathrm{Ne},{ }^{22} \mathrm{Na}$ as a function of depth and size of the meteoroid (Bhattacharya et al $1980 \mathrm{~b}$; Potdar 1981; Bhandari and Potdar 1981). The calculated production profiles of some isotopes are shown in figure 6.

In general, it appears that the production rates increase with depth for $\left(R_{E}<25\right.$ $\mathrm{cm}$ ). For larger meteoroids the isotope production rates increase steeply with depth near the surface giving a broad maximum at about $50 \mathrm{~g} \mathrm{~cm}^{-2}$, followed by a slow decrease in the production rate thereafter as shown in figure 6 . Measurements of particle tracks and radionuclides in several meteorites show a reasonable agreement 


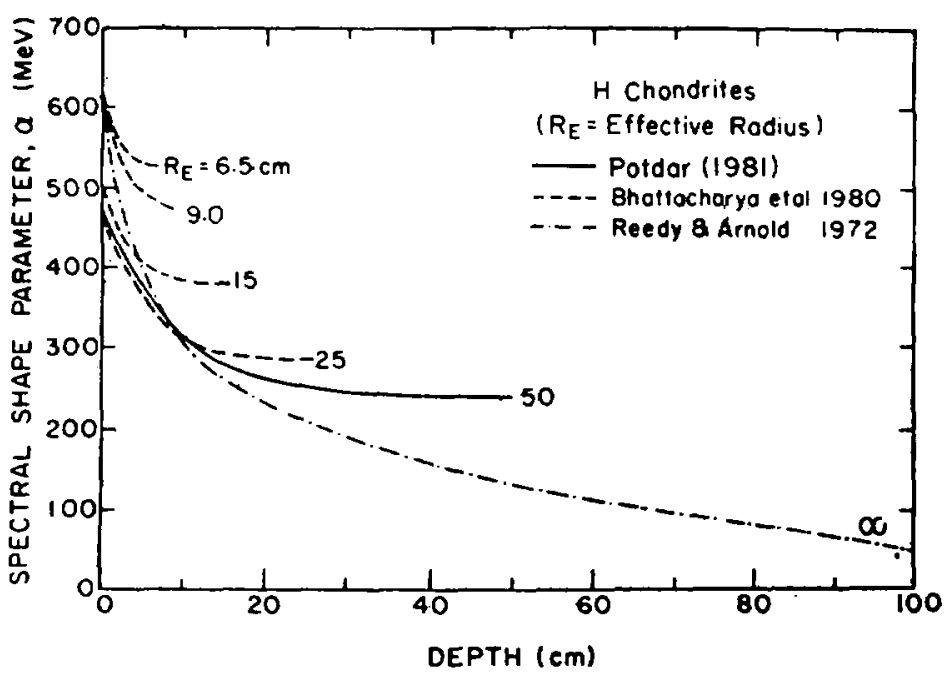

Figure 5. The spectral shape parameter $a$ for meteoroids of various sizes (effective radius $R_{E}$ ) as a function of depth as determined by the observed ${ }^{83} \mathrm{Mn}$ profiles (Bhattacharya et ol 1980) and ${ }^{26} \mathrm{Al}$ profile (Potdar 1981)

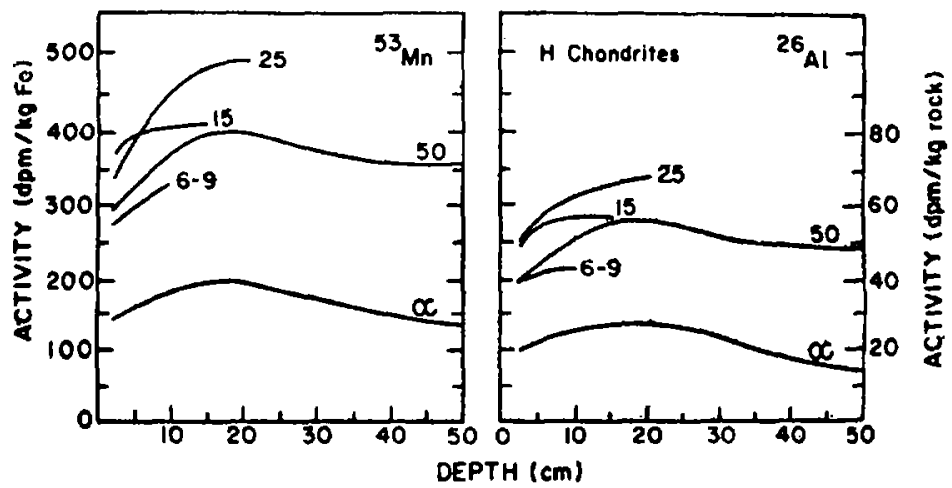

Figure 6a. Calculated production profiles for ${ }^{\mathrm{s}} \mathrm{Mn}$ and ${ }^{20} \mathrm{Al}$ in $\mathrm{H}$-chondrites of various sizes as a function of depth based on the $a$ values given in figure 5 . The production in the top $2 \mathrm{~cm}$ is not given as it is predominantly due to solar cosmic rays.

with the calculated production profiles given in this figure (Potdar 1981; Bhattacharya 1979; Bhandari and Potdar 1981).

By comparing the observed values with the calculations, we can identify meteorites having anomalous radioactivity. Anomalous cases can arise from time variations or intensity variations of GCR in different regions of the interplanetary space. The only well-established variations are due to sunspot cycle. We have calculated (Potdar and Bhandari 1979) the flux $\left(J_{G}>1 \mathrm{GeV}\right)$ of GCR protons measured by balloon and satellite-borne detectors by various workers during the past few decades. During the last solar cycle the GCR flux ( $>1 \mathrm{GeV}$ ) varied between $1.32 \mathrm{p} / \mathrm{cm}^{2} \sec 4 \pi$ sr in 1970 to $2.36 \mathrm{p} / \mathrm{cm}^{2}$. sec $4 \pi \mathrm{sr}$ in 1976 and the data indicate that it is anticorrelated with sunspot numbers with a small phase difference (figure 7). Using the model described above, and the high energy ( $>1 \mathrm{GeV}$ ) fluxes, the production rates of ${ }^{22} \mathrm{Na}$ and ${ }^{54} \mathrm{Mn}$ were calculated for meteoroids of different sizes as a function of time of fall of meteo- 


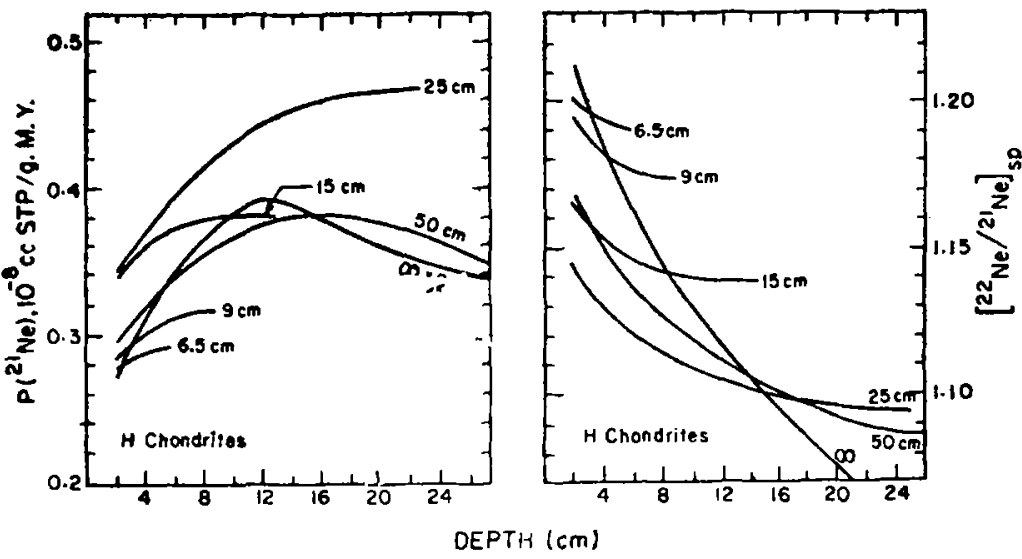

Figure 6b. Calculated depth profiles of ${ }^{21} \mathrm{Ne},{ }^{22} \mathrm{Ne}$ and $\mathrm{NeR}$ in H-chondrites of various sizes (Bhandari and Potdar 1981). The production in the top $2 \mathrm{~cm}$ is not given as it is predominantly due to solar cosmic rays. The solar production has been discussed by Bhandari and Potdar (1981).

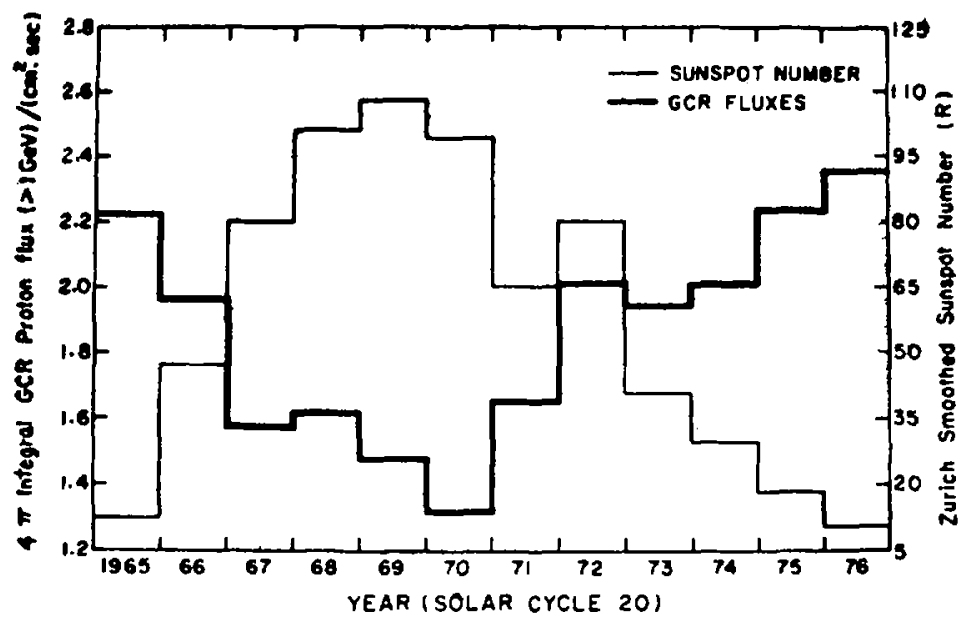

Figure 7. Correlation between sun spot number and the measured GCR flux $(>1$ $\mathrm{GeV}$ ), used in calculation of isotope production rates (Potdar and Bhandari 1979).

rites during the solar cycles 19 and 20 . Activity of these radionuclides expected for a meteoroid of $50 \mathrm{~cm}$ radius at $15 \mathrm{~cm}$ depth as a function of time of fall is shown in figure 8. The curves are in qualitative agreement with the measured profile in several meteorites reported by Evans et al (1979). For a better comparison target abundance, depth and size effect in production must be considered for each sample.

Even when these corrections are applied, some meteorites show significant departure from the expected level for certain nuclides. ${ }^{26} \mathrm{Al}$ and ${ }^{53} \mathrm{Mn}$ are in good agreement in Dhajala chondrite but ${ }^{22} \mathrm{Na}$ and ${ }^{54} \mathrm{Mn}$ (Bhandari et al 1978; Potdar 1981) show anomalously high activity. The activity of ${ }^{22} \mathrm{Na}$ and ${ }^{54} \mathrm{Mn}$ was found to be $25 \%$ and $45 \%$ above the expected level at solar minimum, corresponding to the time of fall of Dhajala. Bhandari et al (1978) have considered the orbital parameters of Dhajala (Ballabh et al 1978) and suggest that relatively low GCR modulation at high 


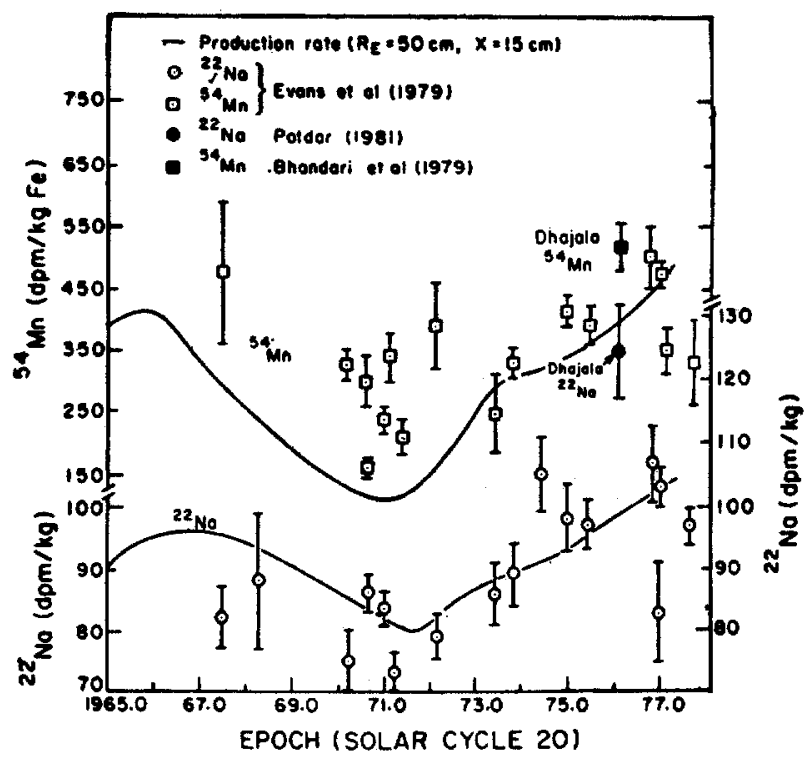

Figare 8. Solar cycle variation of ${ }^{22} \mathrm{Na}$ and ${ }^{54} \mathrm{Mn}$. The calculated curves are from Potdar and Bhandari (1979) and experimental data are from Evans et al (1979) and Bhandari et al (1979).

helioaltitudes during solar minimum can explain the observed activity. There are some otherc hondrites which show marginally anomalous activity and such observations have been usually interpreted as due to time variation of cosmic ray intensity or due to multiple exposure of meteorites. None of these is definitely established so far. We shall discuss the possibility of identifying meteorites with multiple exposures later on.

\subsection{Neutron capture nuclides in meteorites}

Thermal neutron capture reactions produce a large number of stable and radionuclides in meteorites. Eberhardt et al (1963) have shown that low energy neutron source function in meteorites is very different from that of other nucleons and consequently, nuclides produced in neutron capture reactions have production profiles different from spallation nuclides like ${ }^{26} \mathrm{Al},{ }^{21} \mathrm{Ne}$ etc. as shown in figure 6 . The calculations of Eberhardt et al (1963) are however based on ${ }^{4} \mathrm{He}$ production contours in iron meteorites. An attempt to deduce the depth profiles of neutron capture isotopes in chondrites has been made by Bhandari et al (1978) and Potdar (1981). They made a simultaneous measurement of a neutron capture nuclide e.g. ${ }^{80} \mathrm{Co}$ produced in ${ }^{50} \mathrm{Co}$ $(n, \gamma){ }^{60} \mathrm{Co}$ reaction and track density, which provides the preatmospheric depth of a sample, and obtained the depth profile of neutron capture nuclides and the neutron source function. Two chondrites Dhajala (H3) and Allende (C3) have thus been studied in our laboratory. The observed profiles are shown in figure 9 where other available data on these meteorites are also included (see Potdar (1981) for source of data). Dhajala was a small meteoroid in space $\left(R_{E}=50 \mathrm{~cm}\right)$ whereas Allende was bigger, probably having a radius of about a metre. In addition, many fragments 
of the Kirin (H5) chondrite have been extensively studied for track density as well as for several isotopes (Bourot-Denise and Pellas 1981; Honda et al 1980). The ${ }^{60} \mathrm{Co}$ depth profiles in Kirin chondrite and lunar cores (Wahlen et al 1973) are also included in figure 9. The lunar data (Wahlen et al 1973) as well as the calculated profiles (Lingenfelter et al 1972) have been normalized to cobalt abundance of $700 \mathrm{ppm}$, the value used in the meteorite calculations of Eberhardt et al 1963. Allende has cobalt content of $700 \mathrm{ppm}$, Dhajala $730 \mathrm{ppm}$ and Kirin $840 \mathrm{ppm}$. Even after correcting for cobalt abundance the observed depth profiles in the three meteorites are found to be, significantly different. Dhajala has lower activity of ${ }^{60} \mathrm{Co}$ (peak value $80 \mathrm{dpm} / \mathrm{kg}$ ) than expected from the calculations of Eberhardt et al (1963) whereas the peak activity of Allende and Kirin is similar $(225 \mathrm{dpm} / \mathrm{kg}$ ) to the expected values, although the peak positions do not match. The peak in Allende occurs at a much shallower depth $(15 \mathrm{~cm})$ than in Kirin $(30 \mathrm{~cm})$ although their preatmoshperic sizes may be comparable. This is a manifestation of different neutron slowing down lengths in carbonaceous chondrite and $\mathrm{H}$ chondrite because of their different chemical composition. The spallation component in ${ }^{60} \mathrm{Co}$ is very small $(\sim 2 \mathrm{dpm} / \mathrm{kg})$ and thus can be neglected. The discrepancy between the observed and the calculated production profiles of ${ }^{80} \mathrm{Co}$ (Eberhardt et al 1963) is thus quite significant. The available data on other meteorites (Potdar 1981) also support the conclusion that the observed activity of ${ }^{60} \mathrm{Co}$ in small meteorites $(\leqslant 20 \mathrm{~cm})$ is much smaller than the values predicted by Eberhardt et al (1963). It must be emphasized here that ${ }^{\circ 0} \mathrm{Co}$ production is very sensitive to the shape of the meteoroid. The calculations are for spherical bodies and we do not know the shapes of the various meteoroids discussed here. Since an accurate knowledge of the production rates of neutron capture nuclides is essential to determine the preatmospheric sizes (Potdar 1981) and to identify the meteorites with complex exposure, a more detailed study of such nuclides e.g. ${ }^{80} \mathrm{Co},{ }^{36} \mathrm{Cl}$ and ${ }^{50} \mathrm{Ni}$ is desirable.

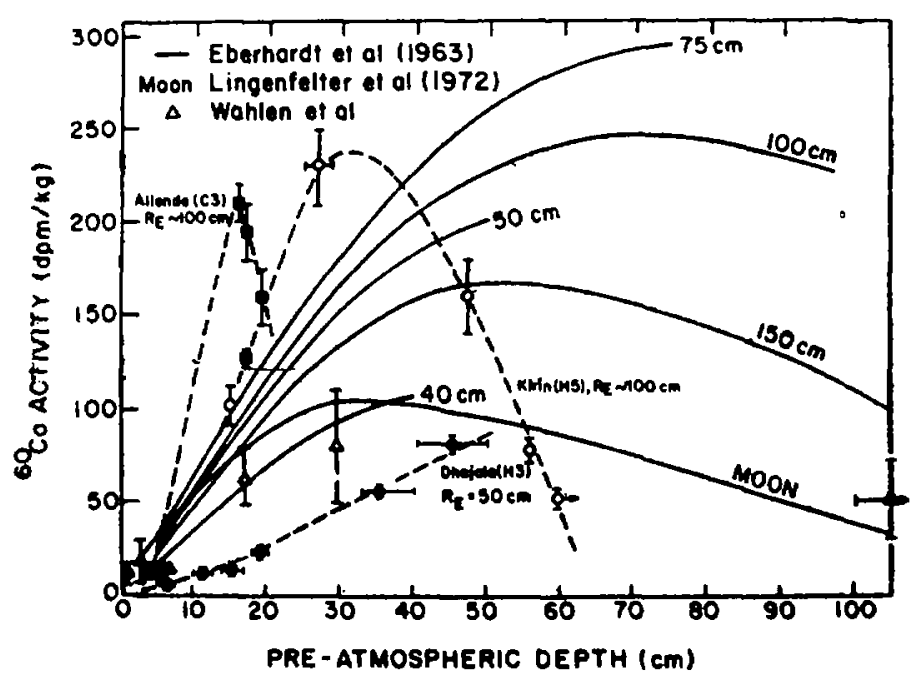

Figure 9. The measured depth profile of ${ }^{\circ} \mathrm{Co}$ in Dhajala $\left(H 3, R_{E}=50 \mathrm{~cm}\right.$ ), Kirin (H5, $\left.R_{E} \cong 100 \mathrm{~cm}\right)$ and Allende $\left(\mathrm{C} 3, R_{E} \cong 100 \mathrm{~cm}\right)$ meteorites. Calculated depth profiles are shown by soild curves (After Eberhardt et al 1963). Dhajala data are from Potdar 1981). 


\section{Multiple exposure of meteorites}

The depth dependence of production rates of cosmic ray tracks, spallation products and neutron capture nuclides is so different that any change in exposure conditions (like geometry, shielding depth etc.) as due to fragmentation in space or reorientation in asteroidal regolith results in easily recognisable effects which are inconsistent with a simple single stage exposure. Such discrepancies have been, in fact, used to describe multiple exposure history of lunar rocks, soils and meteorites. Uncertainty in production rates of nuclides in meteorites, however, has not allowed identification of many cases of marginal multiple exposure.

Bhandari et al $(1980 \mathrm{a}, \mathrm{b})$, based on the fact that the decrease in track production rate (TPM) with depth in a meteorite is steep compared to ${ }^{22} \mathrm{Ne} /{ }^{21} \mathrm{Ne}$ production ratio (NeR), suggested that for a simple exposure, TPM and NeR are correlated, depending mainly on the size of the meteoroid. A quantitative relationship has been obtained by Bhandari and Potdar (1981) and this allows identification of meteorites with complex exposure history as described below.

\subsection{Track production rate-NeR correlation and parent body exposure of chondrites}

The NeR-TPM correlation diagram based on the production profiles of NeR (figure 6, $\S 3$, Bhandari and Potdar 1981) and track density profiles (Bhattacharya et al 1973b; Goswami 1981, figure 1) is shown in figure 10.

Neon ratio and track density have been measured in the same aliquot sample in 41 meteorites. These data are shown in figure 10 . Of these we consider here 22 chondrites whose preatmospheric sizes are known. In the case of 11 meteorites the measured NeR agree with the calculated values indicating that these meteorites (Bishunpur, Ensisheim, Finney, Kiel, Miller, Monze, Paragould, Pulsora, Ramsdorf, Sitathali and Tennasilm) have had single-stage exposure. Grady and Horace have

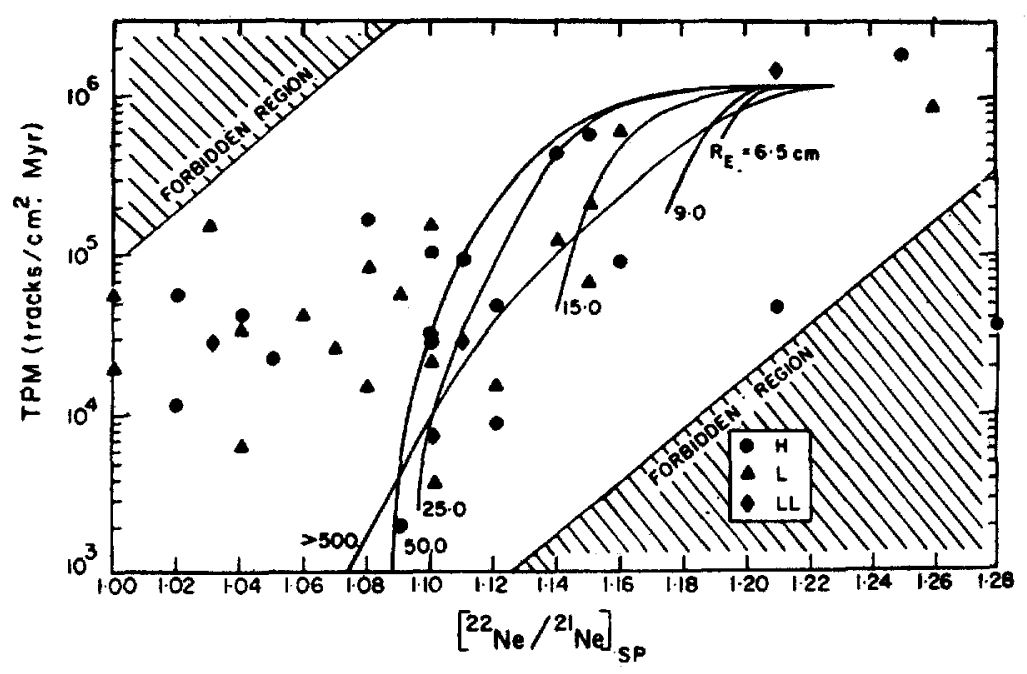

Figure 10. ${ }^{22} \mathrm{Ne} /{ }^{21} \mathrm{Ne}(\mathrm{NeR})$ ys track production rates in $\mathbf{H}$ chondrites of various sizes as a function of depth (Bhandari and Potdar 1981). The data points are from Bhandari et al (1980). 
higher NeR ratios than expected and may represent cases of track annealing. Nine meteorites (De Nova, Gilgoin, Hayes Center, Kesen, Roy, Temple, Ulysses, Walters and Wellman) have lower NeR ratios than expected (Bhandari and Potdar 1981). Since $\mathrm{NeR}$ is independent of exposure age and its measurements are precise, usually within $\pm 2 \%$, the discrepancy between the calculated and measured values is significant. Based on the calculations of production ratio of NeR (Bhandari and Potdar 1981), only a deep-shielded exposure can result in ratios lower than the expected value which is $\geqslant 1.08$ in these cases. Two possibilities of deep-shielded exposure can be visualised (i) in the asteroid regolith, prior to the exposure of the meteoroid as a small body in the interplanetary space or (ii) due to fragmentation in space, in which case the meteoroid is exposed as a part of a larger body for sometime. In both the cases the meteoroid is exposed to cosmic rays for time $T_{1}$ at a shielding depth of $<5 \mathrm{~m}$ (the cosmic ray penetration depth) before it is exposed as an independent body for time $T_{2}$ in the interplanetary space. In view of the current mechanisms for production of meteoroids, such processes must occur frequently as pointed out by Wetherill (1980). Experimentally, however, they can be resolved only if the two exposures produce comparable amounts of spallation neon but significantly different track densities. Since the track production rate decreases steeply with depth, the track density acquired in stage $T_{1}$ will, in general, be orders of magnitude smaller than in stage $T_{2}$. Therefore TPM value will correspond to the final size of the meteoroid. Production rate of rare gas and NeR, on the other hand, decreases slowly with depth and hence, in the case of multiple exposures, the data points will lie to the left of the predicted curves (figure 10) as seen in the case of the nine meteorites listed above.

\subsection{Parent body exposure ages of meteorites and statistical analyses}

Under some plausible assumptions of shielding depths during parent body exposure, it is possible to calculate $T_{1}$, the cosmic ray exposure period in the parent body (or prior to fragmentation) from the observed NeR by using a two-component model.

If $T$ is the exposure age of a meteorite as calculated from ${ }^{21} \mathrm{Ne}$ concentration and $P\left({ }^{21} \mathrm{Ne}\right)$ corresponding to its preatmospheric size $\left(R_{E}\right)$ (figure 6), then, in the case of a complex exposure we can write (Bhandari and Potdar 1981)

$$
T=T_{2}+T_{1} \times P_{R}
$$

where $\quad T_{1}=$ parent body exposure age, (m.y.),

$$
\begin{aligned}
& T_{2}=\text { meteoroid exposure age, (m.y.) and } \\
& P_{R}=\frac{P\left({ }^{21} \mathrm{Ne}\right) T_{1}}{P\left({ }^{21} \mathrm{Ne}\right) T_{2}} \quad \text { i.e. the ratio of }{ }^{21} \mathrm{Ne} \text { production rate }
\end{aligned}
$$

during exposure $T_{1}$ to that during $T_{2}$.

Then

$$
R_{m}=\left(T_{2} / T\right) R_{2}+\left(P_{R} T_{1} / T\right) R_{1},
$$


where

$$
\begin{aligned}
& R_{m}=\text { measured ratio } \mathrm{NeR}=\left({ }^{22} \mathrm{Ne} /{ }^{21} \mathrm{Ne}\right)_{\mathrm{sp}}, \\
& R_{1}=\text { NeR during the exposure } T_{1} \text { and } \\
& R_{2}=\text { NeR during the exposure } T_{2} .
\end{aligned}
$$

Based on this simple two-stage irradiation model in which the depth of irradiation on the parent body is assumed to be 1 metre i.e. $P_{R}=0 \cdot 15$, Bhandari and Potdar (1981) have calculated the approximate values of parent body exposure. These calculations reveal that in about $40 \%$ cases of meteorites, the parent body exposure is significant, and $50 \%$ cases belong to simple exposure. It is possible that some of the simple exposure cases include marginal cases of multiple exposure which cannot be resolved by the technique discussed above.

Although it is ideal to have ${ }^{21,}{ }^{22} \mathrm{Ne}$ and track density measurements in aliquot samples, a statistical analysis can be made from the NeR data alone since according to Bhandari et al (1980b) most meteoroids are small $\left(R_{E}<25 \mathrm{~cm}\right)$. Schultz and Kruse (1978) have compiled the available rare gas data in meteorites. Figure 11 shows a histogram of $\mathrm{NeR}$ for 354 ordinary chondrites which include $166 \mathrm{~L}$ group, $26 \mathrm{LL}$ group and $162 \mathrm{H}$ group chondrites. The histogram shows a peak at $\mathrm{NeR}=1.07$ for $H$ chondrites and at 1.08 for $L$ chondrites. Chondrites with NeR below 1.06 probably represent cases of multiple exposure as these values cannot be attained in small

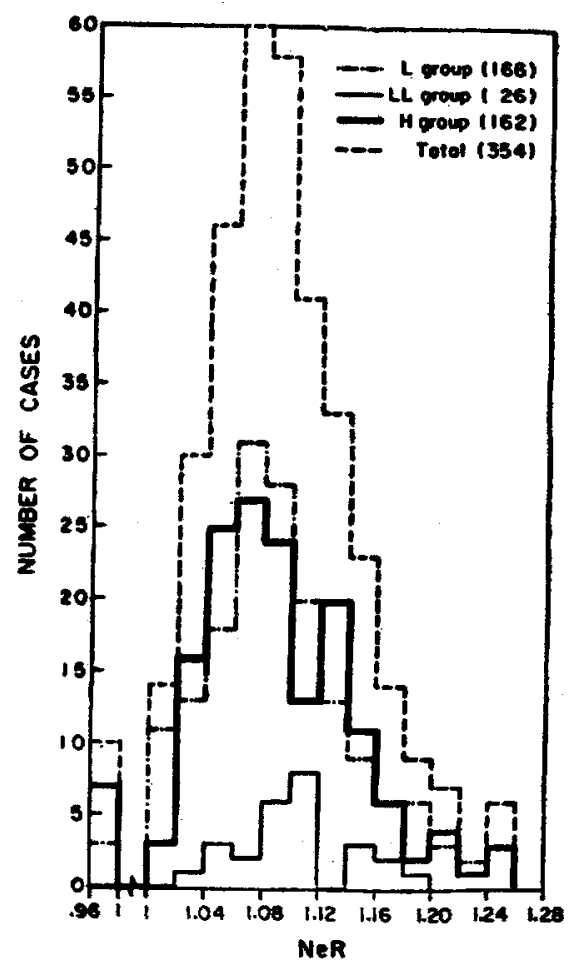

Figure 11. Distribution of spallation ${ }^{12} \mathrm{Ne} /{ }^{21} \mathrm{Ne}(\mathrm{NeR})$ in chondrites based on the compilation of Schultz and Kruse (1978). 
( $<50 \mathrm{~cm}$ radius) meteoroid bodies. Hundred out of 354 chondrites $(28 \%$ ) included in this histogram have NeR $\leqslant 1.06$. Thus 51 out of $162 \mathrm{H}$ chondrites, 45 out of $166 \mathrm{~L}$ chondrites and 4 out of 26 LL chondrites show multiple exposures (Bhandari et al 1981c). If we include other marginal cases, the actual number of meteorites with complex exposure may be larger.

The methods described above clearly indicate that a significant fraction of chondrites has been irradiated to cosmic rays in two or more stages. It should be possible to confirm some of these cases from measurements of radionuclide pairs with short and long half life e.g. ${ }^{28} \mathrm{Al} /{ }^{53} \mathrm{Mn}$ or from neutron effects in rare gases (Fireman 1966). Only a few such measurements are available at present and attempts are being made to include this study in future analyses.

\section{Thermoluminescence of meteorites and lunar samples}

Thermoluminescence has been studied in several meteorites mainly to understand the fading processes associated with atmospheric ablation, proximity of the meteoroid orbits to the sun and terrestrial age or degree of metamorphism (Singhvi et al 1981; Sears 1975; Melcher 1981; Vaz 1972; Sears et al 1980). Similarly the penetration of the diurnal thermal wave on the lunar surface and the flux of solar flare protons have been investigated from a study of TL in lunar rocks and soils (Hoyt et al 1971 1973). The application of TL to these processes requires the knowledge of cosmic ray induced TL gradient or equilibrium dose (ED) as a function of depth in meteoroids of different sizes. It is known that most chondrites, with a few exceptions, show a mean ED of $125 \pm 25$ krads but the depth dependence of ED has not been evaluated so far. We have therefore undertaken a systematic study of TL (ED) profile in meteorite cores in order to evaluate its dependence on the size and the depth of the rocks (Sen Gupta et al 1981). The same meteorites were studied for cosmic ray induced tracks, radionuclides e.g. ${ }^{26} \mathrm{Al}$ or ${ }^{53} \mathrm{Mn}$ and low and high temperature $\mathrm{TL}$. All these data in case of Bansur core are shown in figure 12. The measured TL profiles in Bansur and several other meteorites covering a preatmospheric size range of $6-30 \mathrm{~cm}$ are shown in figure 13. The two opposite faces of Bansur meteorite, labelled SA and SC showed different low temperature TL gradient but high temperature TL was nearly the same except near the fusion crust. Keyes chondrite had negligible dose of low temperature $\mathrm{TL}$, probably due to its long terrestrial age. Thus whereas the low temperature TL(LT) shows depth variation due to heating in the earth's atmosphere and can be related to atmospheric ablation (Singhvi et al 1981), the data indicate that the cosmic ray induced TL (HT) depth profile, (except near the fusion crust) is rather flat. All the four meteorites i.e. Madhipura $\left(R_{E}=6.5 \mathrm{~cm}\right)$, Bansur $(15 \mathrm{~cm})$, St. Severin $(25 \mathrm{~cm})$ and Keyes $(30 \mathrm{~cm})$, however, show different equilibrium doses. St. Severin shows the highest ED of about 200 krads. The production rate of spallogenic nuclides also is not very sensitive to depth (figure $6 \mathrm{a}, \mathrm{b}$ ) but there is a systematic dependence on the size of the meteoroid $(\S 3)$. The dependence of ED on the size does not show any systematic trend. Bar and Herr (1979) have already shown by studying radionuclides and thermoluminescence in thick target bombarded by high energy protons that their production profiles are not identical. Thus although the finer variation of ED for different meteorites, which may depend on the cosmic ray flux and hence the meteorite orbit, is not fully understood, it is clear that the depth dependence and 


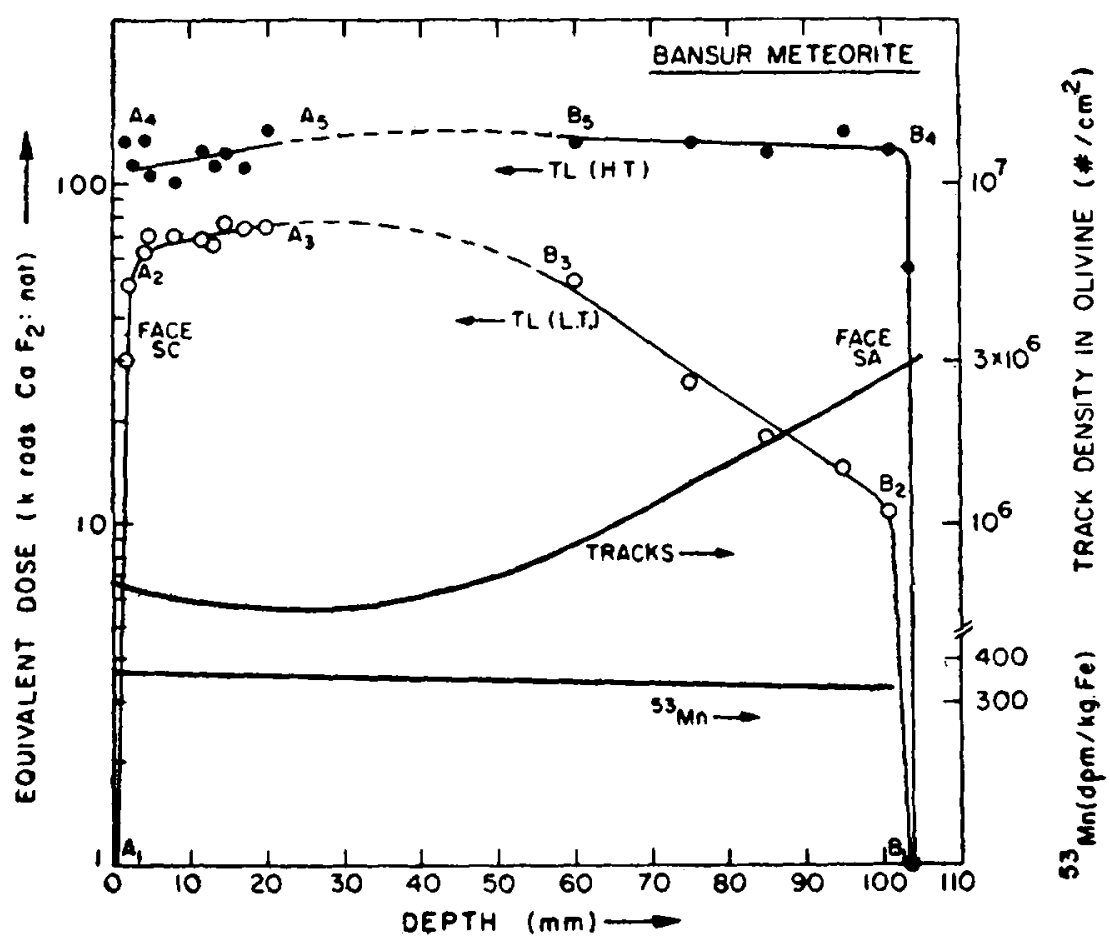

Figure 12. Thermoluminescence (HT and LT) equivalent dose, cosmic ray track den-

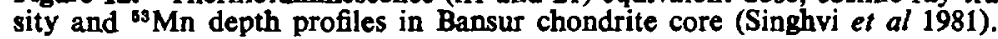

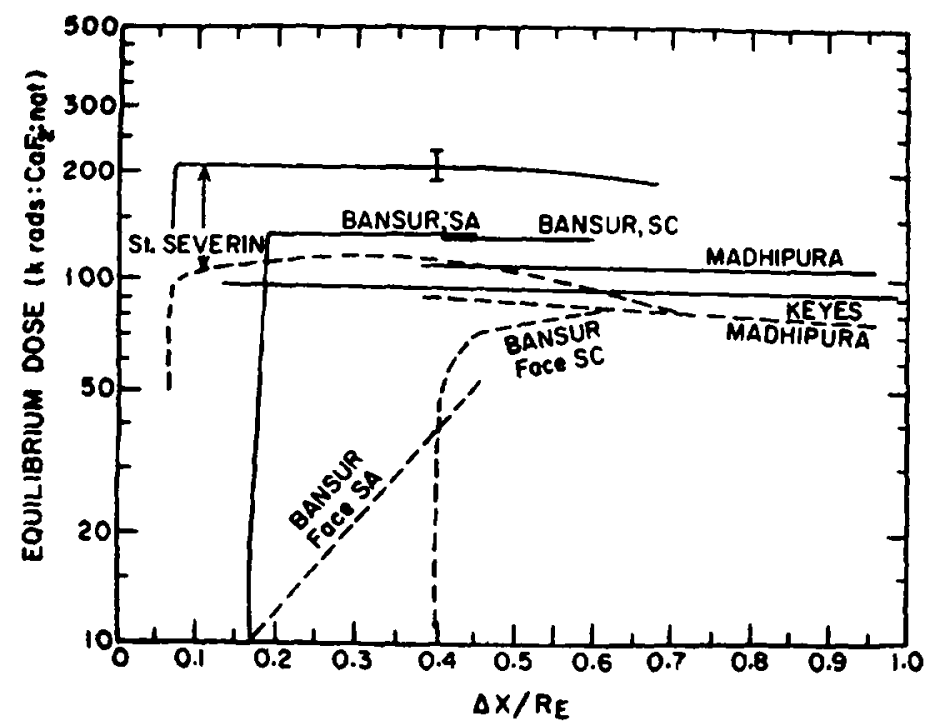

Figure 13. Thermoluminescence equilibrium dose depth profile solid line $=$ high temp. $\left(\sim 300^{\circ} \mathrm{C}\right)$ and dotted line $=$ low temp. $\left(\sim 175^{\circ} \mathrm{C}\right)$ in cores taken from St. Severin $\left(R_{E}=25 \mathrm{~cm}\right)$, Bansur $(15 \mathrm{~cm})$, Madhipura $(6.5 \mathrm{~cm})$ and Keyes $(30 \mathrm{~cm})$ chondrites. $\Delta \boldsymbol{X}$ is the preatmospheric sample depth in the core and $\boldsymbol{R}_{E}$ is the effective radius (Sen Gupta et al 1981; Singhvi et al 1981). The opposite faces of Bansur meteorite, labelled SA and sC show different low temperature TL gradient. Typical error bar is shown on St. Severin curve. Low temperature TL is absent in Keyes chondrite. 
possibly the size dependence are unimportant $(<10 \%)$. The thermoluminescence is induced by low energy (eV) charged particles and photons and the data thus indicate that the flux of such particles is nearly constant with depth.

\section{Future prospects}

The results summarised above show that the work carried out in the past two decades has given us a general idea about several characteristics of cosmic rays e.g. flux of solar and galactic cosmic rays, their time and spatial variations and some aspects of their composition (Lal 1972, 1977; Schaeffer 1975; Bhandari and Rao 1980). More quantitative information with better time resolution is, however, necessary to understand the processes related to the origin of cosmic rays.

The basic alternatives proposed for the origin of GCR are still being debated. The contribution due to r-process synthesis in supernovae explosions, in $s$-process synthesis in stellar interiors or due to acceleration of interstellar material is still not resolved. Some isotopic and elemental abundances are so characteristic of these processes that the nucleosynthetic processes responsible for production of cosmic rays can be resolved, if the isotopic ratio of certain elements can be measured. Enormous effort is being made currently in this direction using particle detectors, aboard satellites and spacecrafts (Mewaldt et al 1979; Garcia-Munoz and Simpson 1979). Recent advances in experimental techniques for single atom detection (Hurst et al 1979) now make it possible to look into this problem much more effectively by taking advantage of the high cosmic ray dose received by lunar samples and meteorites. One of the possibilities is to study $\mathrm{Pu}$ and $\mathrm{Cm}$ isotopes in cosmic rays which we discuss in detail below.

\subsection{Resonance ionisation spectroscopy (RIS) of Pu and $\mathrm{Cm}$ isotopes using meteorite and lunar samples}

Relative abundances of heavy ions, particularly transuranic nuclei, in cosmic rays hold clue to their origin, acceleration and propagation. Some of these elements are produced exclusively in $r$-process nucleosynthesis and others in $r, s, p$ and $n$ processes or explosive nucleosynthesis, their abundances depending sensitively on the density, temperature and seed nuclei present in the stellar shell where they are believed to be formed. Direct measurements of cosmic ray composition using nuclear detectors indicate the presence of heavy nuclei, probably upto uranium, but the presence of transuranic nuclei, although expected, is still inconclusively demonstrated (Fowler et al 1979). Isotopic ratios of light nuclei, e.g. Ne, Mg. etc. have been measured (Garcia-Munoz et al 1979; Mewaldt et al 1979) but they are not so distinctly characteristic of different nucleosynthetic processes. Of the various nuclei formed in nucleosynthesis we consider here $\mathrm{Pu}, \mathrm{Cm}$ (and possibly $\mathrm{Tc}$ ) isotopes, whose relative abundances are characteristic of nucleosynthetic processes and which can be measured using RIS technique as described below, using lunar and meteorite samples.

Meteorites and lunar samples are exposed to cosmic rays for long periods of time $\left(10^{6}-10^{9} \mathrm{yr}\right)$ so that they contain the implanted cosmic ray nuclei in the most enriched form found anywhere in the solar system. 
$\mathrm{Pu}, \mathrm{Cm}$ and $\mathrm{Tc}$ (in addition to $\mathrm{Pm}$ ) are unstable nuclei and their natural abundance on earth is zero. Tc and $\mathrm{Pm}$ can be produced in some rare nuclear interactions on the earth at extremely low levels but $\mathrm{Pu}$ and $\mathrm{Cm}$ cannot be produced. Thus although the solar system abundance of these nuclei is negligible, the cosmic ray abundance may be significant. Considering only isotopes with half life greater than a year, we find that $\mathrm{Pu}$ has several such isotopes: ${ }^{286} \mathrm{Pu}(2 \cdot 85 \mathrm{y}),{ }^{238} \mathrm{Pu}(87 \cdot 8 \mathrm{y}),{ }^{239} \mathrm{Pu}\left(2 \cdot 4 \times 10^{4} \mathrm{y}\right)$, ${ }^{240} \mathrm{Pu},(6540 \mathrm{y}),{ }^{241} \mathrm{Pu}(15 \mathrm{y}),{ }^{242} \mathrm{Pu}\left(3.8 \times 10^{5} \mathrm{y}\right)$ and ${ }^{244} \mathrm{Pu}\left(8.3 \times 10^{7} \mathrm{y}\right) ; \mathrm{Cm}$ isotopes ${ }^{243} \mathrm{Cm}(28 \mathrm{y}),{ }^{244} \mathrm{Cm}(17.9 \mathrm{y}),{ }^{245} \mathrm{Cm}\left(4.8 \times 10^{3} \mathrm{y}\right),{ }^{246} \mathrm{Cm}\left(4.7 \times 10^{3} \mathrm{y}\right),{ }^{247} \mathrm{Cm}$ $\left(1.5 \times 10^{7} \mathrm{y}\right),{ }^{248} \mathrm{Cm}\left(3.5 \times 10^{5} \mathrm{y}\right),{ }^{260} \mathrm{Cm}\left(1.1 \times 10^{4} \mathrm{y}\right) ;$ Tc isotopes ${ }^{97} \mathrm{Tc}\left(2.6 \times 10^{6} \mathrm{y}\right)$, ${ }^{88} \mathrm{Tc}\left(1.5 \times 10^{6} \mathrm{y}\right),{ }^{99} \mathrm{Tc}\left(2.13 \times 10^{5} \mathrm{y}\right)$ and $\mathrm{Pm}$ isotopes ${ }^{145} \mathrm{Pm}(18 \mathrm{y}),{ }^{146} \mathrm{Pm}(4.4 \mathrm{y})$ and ${ }^{147} \mathrm{Pm}(2.62 \mathrm{y})$ are other isotopes with half life greater than a year.

Cosmic ray abundance of $\mathrm{Pu}$ and $\mathrm{Cm}$ can be calculated from nucleosynthetic yield and meteorite data. $\mathrm{U}: \mathrm{Pu}: \mathrm{Cm}$ are expected to be produced in about equal quantities in freshly synthesised material (Hillebrandt 1978). Since Fe abundance is known accurately in the solar system and in cosmic rays, we will calculate other abundances relative to $\mathrm{Fe}$. U/Fe in solar system is $2.5 \times 10^{-8}$ (Cameron 1970). Taking cosmic ray abundance of $U$ and $\mathrm{Fe}$ to be the same as in solar system we expect $\mathrm{Pu} / \mathrm{Fe}$ and $\mathrm{Cm} / \mathrm{Fe}$ to be of the order of $10^{-8}$. The iron group nuclei of galactic cosmic ray origin observed in stone meteorites with typical exposure age of $10^{7} \mathrm{yr}(e . g$. St. Severin) (Bhandari et al 1980b) range upto $10^{7} / \mathrm{cm}^{2}$. Using the range of $\mathrm{Fe}$ group nuclei in silicate minerals as $15 \mu \mathrm{m}$, their concentration is expected to be $7 \times 10^{9} \mathrm{Fe} / \mathrm{cc}$ or $2 \times 10^{\circ}$ $\mathrm{Fe}$ nuclei/g rock. Pu and $\mathrm{Cm}$ therefore should occur at the level of 20 atoms $/ \mathrm{g}$ in such meteorites. Some of these nuclei might undergo fragmentation in the rock material. The fragmentation is energy-dependent and only $\simeq 20 \%$ particles may survive unfragmented. Thus we expect a few atoms of $\mathrm{Pu}$ and $\mathrm{Cm}$ in stony meteorites and lunar samples. Their number may be somewhat larger (factors of 2 to 10) in iron meteorites because of their longer exposure ages. The calculated values of $\mathrm{Tc} / \mathrm{Fe}=5 \times 10^{-5}$ and $\mathrm{Pm} / \mathrm{Fe}=10^{-6}$ lead to concentration of $10^{2}-10^{4}$ atoms $/ \mathrm{g}$ for Tc and Pm.

All these nuclei do not survive the time galactic cosmic rays take in reaching the earth. The mean propagation time is $1.6 \times 10^{7}$ years in the interstellar space as determined from the isotopic ratios of Be (Garcia Munoz and Simpson 1979). Although local contribution from freshly synthesised material in cosmic rays is possible, of the isotopes mentioned above only ${ }^{244} \mathrm{Pu}$ and ${ }^{247} \mathrm{Cm}$ are likely to survive the average life time of cosmic rays.

The three nuclides mentioned above can be easily detected using schemes 1 and 3 of Hurst et al (1979) as shown in table 2. The experimental technique involves a

Table 2. Expected concentration of cosmic ray implanted isotopes in meteorites and lunar samples.

\begin{tabular}{lclc}
\hline Isotope & $\begin{array}{c}\text { Cosmic ray } \\
\text { abundance } \\
\text { relative to iron }\end{array}$ & $\begin{array}{l}\text { Expected (1) } \\
\text { concentration } \\
\text { atom/g rock }\end{array}$ & $\begin{array}{c}\text { RIS } \\
\text { scheme } \\
(2)\end{array}$ \\
\hline Cm $(247)$ & $1.8 \times 10^{-8}$ & $\sim 5$ & 1 \\
Pu $(244)$ & $2 \times 10^{-8}$ & $\sim 5$ & 1 \\
Tc $(97,98,99)$ & $5 \times 10^{-8}$ & $10^{2}-10^{3}(3)$ & 3 \\
\hline
\end{tabular}

(1) In shallow samples of meteorites with GCR exposure age of $\geqslant 10 \mathrm{~m} . \mathrm{y}$.

(2) Hurst et al (1979).

(3) Assuming fresh injection at time scales comparable to the half life of isotopes. 
suitable step by which either the meteorite or lunar sample atoms can be directly introduced into a proportional counter or the elements of interest can be first chemically enriched and then introduced in the chamber. Scheme $1 \mathrm{~A}\left(\omega_{1}, \omega_{1} e^{-}\right) A^{+}$is the simplest of all, using a single frequency laser and the time coincidence is assured $\mathrm{Pu}$ and $\mathrm{Cm}$ can thus be selectively and unambiguously ionised and identified using this scheme. Scheme 3 for Tc A $\left(\omega_{1}, \omega_{2}, \omega e^{-}\right) A^{+}$is comparatively more complicated requiring two or more lasers.

Thus it appears that RIS can be effectively used to detect $\mathrm{Cm}$ and $\mathrm{Pu}$ atoms implanted in meteorites and lunar samples. Their concentration should provide parameters relating to the origin of cosmic rays and enable us to distinguish various channels of their synthesis. Although these are difficult experiments, they appear feasible and will provide a new insight into the ancient records of cosmic rays in extraterrestrial rocks.

\section{Acknowledgements}

The author is indebted to Dr G S Hurst and Dr J N Goswami for useful discussions and to Dr P N Shukla, Dr A K Singhvi, Mr M B Potdar and Mr D Sen Gupta for providing unpublished results and valuable help in writing this article. Thanks are due to Mr K M Suthar for assistance.

\section{References}

Ballabh G M, Bhatnagar A and Bhandari N 1978 Icarus 33361

Bar K and Herr W 1974 Earth Planet. Sci Lett. 22188

Begemann F, Born W, Palune H, Vilcsek E and Wanke H 1972 Proc. Lunar Sci. Conf. 3rd. (New York: Pergamon Press) p. 1963

Behrman C, Crozaz G, Drozd R, Hohenberg C, Ralston C, Walker R and Yuhas D 1973Proc. Lunar Sci. Conf. 4th. (New York: Pergamon Press) p. 1957

Bhandari N 1977 Proc. Lunar Sci. Conf. 8th. (New York: Pergamon Press) p. 3607

Bhandari N, Bhat S, Lal D, Rajagopalan G, Tamhane A S and Venkatavaradan V S 1971 Proc. Lunar Sci. Conf. 2nd (Massachusetts: MIT Press) p. 2611

Bhandari N, Bhattacharya S K and Padia J T 1975 Proc. Lunar Sci. Conf. 6th. (New York: Pergamon Press) p. 1913

Bhandari N, Bhattacharya S K and Padia J T 1976 Proc. Lunar Sci. Conf. 7th. (New York: Pergamon Press) p. 513

Bhandari N, Bhattacharya S K and Somayajulu B L K 1978 Earth Planet. Sci. Lett. 40194

Bhandari N, Lal D, Goswami J. N 1976 Unpublished

Bhandari N, Lal D, Nautiyal C M, Padia J T, Potdar M B, Rao M N and Venkatesan T R 1980a Meteoritics 15265

Bhandari N, Lal D, Rajan R S, Arnold J R, Marti K and Moore C B 1980b Nucl. Track 4213

Bhandari N, Potdar M B and Shukla P N 1981b Lunar Planet. Sct. XII (Houston: Lunar Planet Inst.) p. 62

Bhandari N, Potdar M B and Suthar K M 1981c Meteoritics 16293

Bhandari N and Rao M N 1980 Proc. Indian Acad. Sci. (Earth Planet. Sci.) 89121

Bhandari N and Potdar M B 1982 Earth Planet. Sci. Lett. 57143

Bhattacharya S K 1979 cosmic ray characteristics based on induced radioactivity in lunar samples and meteorites, Ph. D Thesis, Gujarat University, Ahmedabad.

Bhattacharya S K and Bhandari N 1975 Proc. Lunar Sci. Conf. 6th. (New York: Pergamon Press) 1901

Bhattacharya S K, Bhandari N and Perelygin V P 1980a J. Geophys. Res. 851439 
Bhattacharya S K, Imamura M, Sinha N and Bhandari N 1980b Earth Planet. Sci. Lett. 5145

Bhattacharya S K, Goswami J N and Lal D 1973b J. Geophys. Res. 788356

Bhattacharya S K, Goswami J N, Gupta S K and Lal D 1973a The Moon 8253

Boeckl R S 1972 Earth Planet. Sci. Lett. 1626

Bourot-Denise M and Pellas P 1981 Meteoritics 16297

Cameron A G W 1970 Sp. Sci. Rev. 15121

Clayton D D, Fowler W A, Hull T E and Zimmerman B A 1961 Ann. Phys. 17331

Cressy P J Jr and Bogard D D 1976 Geochim. Cosmochim. Acta 40749

Dust S and Crozaz G 1977 Proc. Lunar Sci. Conf. 8th. (New York: Pergamon Press) p. 2315

Eberhardt P, Geiss J and Lutz H 1963 In Earth science and meteoritics, (ed.) J Geiss and E D Goldberg, (Amsterdam: North Holland) p. 143

Evans J C, Rancitelli L A, Reeves J H and Bogard D D 1979 Abstracts of papers presented at the Conf. on Ancient Sun (Houston: Lunar Planet. Inst.) p. 28

Finkel R C 1972 Depth profiles of galactic cosmic ray produced radionuclides in lunar samples Ph.D. Thesis, University of California San Diego

Fireman E L 1966 Z. Naturforsch. A21 1138

Fowler P H, Clapham V M, Henshaw D L, Thompson A and O'Sullivan D 1979 Proc. 16th. Int. Conf. on Cosmic Rays, 6 (Tokyo: Univ. of Tokyo) p. 370

Fruchter J S, Rancitelli L A and Perkins R W 1976 Proc. Lunar Sci. Conf. 7th. (New York: Pergamon Press) p. 127

Fruchter J S, Evans J C, Reeves J H and Perkins R W 1981 Lunar and Planet. Sci. XII (Houston: Lunar Planet. Inst.) p. 774

Garcia-Munoz M and Simpson J A 1979 Proc. 16th. Int. Conf. on Cosmic Rays 1 (Kyoto: Univ. of Tokyo) p. 270

Goswami J N, Jha R and Lal D 1981 J. Astrophys. Astr. 2201

Goswami J N 1981 Proc. Indian Acad. Sci. (Earth Planet. Sci.) 90345

Hillebrandt W 1978 Space Sci. Rev. 21639

Honda M, Horie R, Imamura M, Nishiizumi K, Takaoka N and Konura K 1980 Geochem. J. 14 82

Hoyt H P Jr, Miyajima M, Walker R M, Zimmerman D W and Zimmerman J 1971 Proc. Lunar Sci. Conf. 2nd. (New York: Pergamon Press) p. 2245

Hoyt H P Jr, Walker R M and Zimmerman DW 1973 Proc. Lunar Sci. Conf. 4th. (New York: Pergamon Press) p. 2489

Hurst G S, Payne M G, Kramer S D and Young J P 1979 Rev. Mod. Phys. 51767

Kohl C P, Murrel M T, Russ G P III and Arnold J R 1978 Proc. Lunar Sci. Conf. 9th. (New York: Pergamon Press) p. 2299

Kohman T P and Bender M L 1967 in High energy nuclear reactions in astrophysics (ed.) B S P Shen, (New York: Benjamin) p. 169

Kondrateyev K Y and Nikolosky G A 1970 Q.J. R. Met. Soc. 569

Lal D 1972 Sp. Sci. Rev. 143

Lal D 1977 Philos. Trans. R. Soc. London A285 69

Lavrukhina A K and Ustinova G K 1972 Earth Planet Sci. Lett. 15347

Lingenfelter R E, Canfield H and Hampel V E 1972 Earth Planet. Sci. Lett. 16355

Melcher C L 1981 Earth Planet. Sci. Lett. 5239

Mewaldt R A, Spalding J D, Stone E C and Vogt R E 1979 Proc. 16th. Int. Conf. on Cosmic Rays 7 (Tokyo: Univ. of Tokyo) p. 382

Nautiyal C M, Padia J T, Rao M N, Venkatesan T R 1981 Proc. Lunar and Planet. Sci. Conf. $12 t h$.

Nishiizumi K and Arnold J R 1981 Lunar and Planet. Sci. XII (Houston: Lunar Planet. Inst.) p. 3061

Potdar M B 1981 Nuclear interactions of the solar and galactic cosmic rays with interplanetary materials Ph.D. Thesis, Gujarat University, Ahmedabad

Potdar M B and Bhandari N 1979 Proc. Indian Natl. Sci. Acad. A45 32

Rancitelli L A, Fruchter J S, Felix W D, Perkins R W and Wogman N A 1975 Proc. Lunar. Sci. Conf. 6th. (New York: Pergamon Press) p. 1891

Reedy R C 1977 Proc. Lunar Sci. Conf. 8th (New York: Pergamon) p. 825 
Reedy R C 1980 Proc. Conf. on Ancient Sun, (eds.) R O Pepin, J A Eddy and R M Merrill (New York: Pergamon Press) p. 365

Reedy R C and Arnold J R 1972 J. Geophys. Res. 77537

Reedy R C, Arnold J R and Lal D 1981 Science (in press)

Regnier S, Hohenberg C M, Marti K and Reedy R C 1979 Proc. Lunar Sci. Conf. 10th. (New York: Pergamon) p. 1565

Schaeffer O A 1975 Proc. 14th Int. Cosmic ray conf. 11 (Munich: Max-Plank Inst.) p. 3508

Schultz L and Kruse H 1978 Nucl. Track Detection 265

Sears D W 1975 Mod. Geol. 5155

Sears D W, Grossman J N, Melcher C L, Ross L M and Mills A A 1980 Nature (London) 287791

Sengupta D, Bhandari $N$ and Singhvi A K 1981 in preparation

Singhvi A K, Pal S and Bhandari N 1981 Proc. Conf. on TL Symposium (Oxford) PACT (in press).

Tobailem J 1977 Note CEA-N-1466 (4) 45 Centre d'Etudes Nucleaires de Saclay, France

Vaz J E 1972 Meteoritics 777

Venkatesan T R, Nautiyal C M, Padia J T and Rao M N 1980 Proc. Lunar Sci. Conf. 11th. (New York: Pergamon Press) p. 1271

Wahlen M, Honda M, Imamura M, Fruchter J S, Finkel R C, Kohl CP, Arnold J R and Reedy R C 1972 Proc. Lunar Sci. Conf. 3rd. (New York: Pergamon Press) p. 1719

Wahlen M, Finkel R C, Imamura M, Kohl C P and Arnold J R 1973 Earth Planet. Sci. Lett. 19 315

Walker R M 1975 Annu. Rev. Earth Planet. Sci. 399

Wetherill G W 1980 Meteoritics 15386

Woosley S E, Arnett W D and Clayton D D 1978 Astrophys. J. 26231

Yaniv A 1981 Nature (London) 292866

Yaniv A and Marti K 1981 Astrophys. J. Lett. 247 L143

Yuhas D and Walker R 1973 Proc. 13th Int. Conf. on Cosmic Rays 2 (Denver: Univ. of Denver) p. 1116

Zook H A 1980 Proc. Conf. on Ancient Sun (eds.) R O Pepin, J A Eddy and R M Merrill (New York: Pergamon Press) p. 245 